\title{
Effects of endoscopic submucosal dissection on post-operative early treatment effectiveness and serum TAT-2 and GP73 expression levels in patients with early gastric cancer
}

\author{
XUE HUANG $^{1}$, FUJIAN LIU ${ }^{1}$, HANG GUAN ${ }^{1}$, ZHIYONG JIANG ${ }^{1}$, PENG WEI ${ }^{2}$, \\ YIFENG LUO ${ }^{3}$ and QIUHONG JIA ${ }^{1}$
}

Departments of ${ }^{1}$ Gastroenterology, ${ }^{2}$ Respiratory and Critical Care Medicine and ${ }^{3}$ Intensive Care Unit, The Eighth Affiliated Hospital of Guangxi Medical University, Guigang, Guangxi 537100, P.R. China

Received September 24, 2019; Accepted October 6, 2020

DOI: $10.3892 / \mathrm{etm} .2021 .10238$

\begin{abstract}
The present study aimed to explore the effectiveness of endoscopic submucosal dissection (ESD) in the treatment of early gastric cancer (EGC) and its effect on serum tumor-associated trypsin-2 (TAT-2) and Golgi protein 73 (GP73) expression levels to provide a reference for the treatment of EGC.TAT-2 is a proteolytic target enzyme for tumor-associated trypsin inhibitor that has been previously reported to enhance invasion by promoting extracellular matrix degradation. GP73 is a novel type II Golgi membrane protein of unknown function that is expressed in the hepatocytes of patients with adult giant-cell hepatitis. A total of 161 patients with EGC treated at our hospital from April 2013 to February 2014 were selected as the study subjects. Among these, 86 patients underwent ESD (group A) and the remaining 75 underwent endoscopic mucosal resection (group B). Treatment effectiveness, incidence of complications and adverse reactions, operation time, intraoperative blood loss and length of hospital stay, as well as serum TAT-2 and GP73 expression levels, were compared between the two groups. The treatment effectiveness was significantly higher in group $\mathrm{A}$ than in group $\mathrm{B}(\mathrm{P}<0.05)$. However, there was no significant inter-group difference in terms of incidence of complications/adverse reactions $(\mathrm{P}>0.05)$. After treatment, serum TAT-2 expression levels decreased in both groups $(\mathrm{P}<0.05)$ and serum TAT-2 expression levels were lower in group $\mathrm{A}$ than in group $\mathrm{B}(\mathrm{P}<0.05)$. Furthermore, serum GP73 expression levels were significantly elevated in both groups $(\mathrm{P}<0.05)$. Kaplan-Meier survival analysis indicated no significant inter-group difference in the 5-year survival rate $(\mathrm{P}>0.05)$. In conclusion, ESD had a good therapeutic effect on
\end{abstract}

Correspondence to: Dr Qiuhong Jia, Department of Gastroenterology, The Eighth Affiliated Hospital of Guangxi Medical University, 1 Zhongshan Middle Road, Guigang, Guangxi 537100, P.R. China

E-mail: fuzljcf@163.com

Key words: early gastric cancer, endoscopic submucosal dissection, trypsinogen-2, Golgi protein 73
EGC and is able to decrease serum TAT-2 expression levels and increase serum GP73 expression levels. The present study was registered into the Chinese Trials Registry (registration no. NCT02157534).

\section{Introduction}

Gastric cancer (GC) is a common malignant tumor type of the digestive system. Its incidence is the fifth-highest among all malignant tumors and GC is the third leading cause of cancer-associated mortality worldwide (1). A survey conducted by the National Central Cancer Registry of China reported $\sim 410,000$ novel cases of GC in China annually and $\sim 290,000$ GC-associated deaths (2). Despite the downward trend in the overall incidence and mortality related to GC due to the gradual improvement in diagnosis and treatment strategies (3), reduction of Helicobacter pylori infection due to better hygiene and antibiotics use and a deeper understanding of its molecular mechanisms, it still poses enormous challenges $(4,5)$.

Early GC (EGC) refers to gastric lesions confined to the gastric mucosa or submucosa (6). Studies have indicated that radical surgery, primarily endoscopic submucosal dissection (ESD) and endoscopic mucosal resection (EMR), are the optimal surgical approach for patients with GC $(7,8)$. ESD has advantages of minimal invasiveness and high treatment efficiency. Furthermore, ESD has a good therapeutic effect on a relatively wide range of tissues wherein pathological examination may determine the residual cancer cell status $(9,10)$.

Golgi protein 73 (GP73), initially isolated from a complementary DNA liver library of patients with Cytomegalovirus hepatitis, is a protein unique to epithelial cells. It is abnormally expressed in hepatocarcinoma, bile duct carcinoma and lung cancer (11-13). Trypsinogen-2 (TAT-2) is a serine protease encoded by T- 8 amino acid, which is closely associated with the growth and metastasis of cancer cells. It is able to activate proteases and receptors. Receptors are present on different tumor cells, as well as on cells that form the tumor microenvironment, including vascular endothelial cells, smooth muscle cells and macrophages that promote tumor growth and development $(14,15)$. Ichikawa et al $(16)$ reported that serum TAT-2 expression levels were higher in patients with 
Borrmann type IV GC/leucogastric cancer than in those with other GC types; furthermore, they reported that it may be associated with lymph node metastasis, liver metastasis and poorly differentiated adenocarcinoma.

The treatment of patients with EGC using ESD has been extensively studied $(17,18)$, whereas limited progress has been made regarding the specific therapeutic effect of treatment for EGC using ESD and its effect on serum TAT-2 and GP73 expression levels. Therefore, the present study aimed to observe the early treatment effectiveness of ESD and the effect on TAT-2 and GP73 expression levels in patients with EGC to provide a reference for clinical treatment.

\section{Materials and methods}

General patient information. A total of 161 patients with EGC treated at the Eighth Affiliated Hospital of Guangxi Medical University (Guigang, China) from April 2013 to February 2014 were selected as the study subjects. Patients who underwent ESD were assigned to group A (86 cases), and those who underwent EMR were assigned to group B ( 75 cases). There were 56 males and 30 females in group A (age, 46-61 years; mean age, $57.36 \pm 2.87$ years). There were 17 cases of lymph node metastasis, 69 cases without lymph node metastasis, 36 cases with tumor infiltration of the mucosal layer, 19 cases with tumor infiltration of the superficial muscle layer and 31 cases with tumor infiltration of the submucosal layer. In group B, there were 48 males and 37 females (age, 43-60 years; mean age, $58.06 \pm 2.84$ years). There were 19 cases of lymph node metastasis, 5 cases without lymph node metastasis, 33 cases with tumor infiltration of the mucosal layer, 15 cases with tumor infiltration of the superficial muscle layer and 27 cases with tumor infiltration of the submucosal layer. The present study was approved by the Ethics Committee of the Eighth Affiliated Hospital of Guangxi Medical University (Guigang, China). All study participants provided written informed consent prior to participating in the study.

Inclusion and exclusion criteria. The inclusion criteria were as follows: Patients aged 40-65 years; first diagnosed with EGC using gastroscopy and histopathological examination without prior treatment prior to admission; no lesion size limits were applied in the patient selection process; diagnosed with EGC with the GC differentiation degree, clinical stage and lymph node metastasis being in accordance with the criteria of the Union for International Cancer Control for EGC (19). The family members of all patients were informed and patients or family members provided written informed consent. Patients with congenital immune dysfunction, severe birth defects, other heart, liver or kidney diseases or with coagulation disorders were excluded.

Treatment. An electronic gastroscope (Olympus Corp.) was used with the $\mathrm{Cv}-260$ endoscope host. The ultrasonic microprobe (model no. ERBEICC-200) was set to $20 \mathrm{MHz}$. A high-frequency electrotome, injection needle, hemostatic clamp, trap, three-claw forceps and hot biopsy forceps were also used in the surgical procedures. After admission of all study subjects, group B was treated using EMR as follows: High-frequency electroacupuncture was performed to electrocauterize around the lesion and mark the edge. Next, a submucosal injection of
1:10,000 epinephrine/normal saline was administered (1 ml). Next, a trap was placed around the lesion after confirming lesion swelling. The lesion tissue was lifted with three-claw forceps and the trap was retrieved. Finally, the lesion was excised, the endoscope was removed and relevant tissues were examined pathologically for residual GC cells $(2,4)$. Group A received ESD as follows: A 1:10,000 mixture of adrenaline/normal saline was injected under the lesion mucosa $(1 \mathrm{ml})$ and the lesion location was aspirated by a transparent cap after the lesion swelling was confirmed. Next, dissection was performed along the lesion edge, the tumor was removed and bleeding was stopped by electrocoagulation after using an electrical trap. Finally, the tissue was examined pathologically for residual GC tissue $(5,6)$. All patients were post-operatively administered routine hemostatic and anti-infection treatments. The patients fasted for 1 day post-operatively and proton pump inhibitors were routinely administered for 2 weeks. The patients were also treated with gastric mucosal protective agents.

Treatment effectiveness. After 2 weeks, symptoms and treatment effectiveness were evaluated on a descriptive scale (20): i) Markedly effective - symptoms, signs and lesions disappeared and imaging and endoscopic findings were normal; ii) effective - symptoms and signs improved, imaging and endoscopic findings improved and lesions were smaller than those prior to treatment; and iii) ineffective - symptoms and signs did not improve, the fistula exhibited no change or increased according to imaging and endoscopic examination and the condition had a progressive trend toward deterioration. The incidence of post-operative complications was also recorded (21).

Main reagents. A TAT-2 diagnostic kit (cat. no. YS01266B; Shanghai Yaji Biotechnology Co., Ltd.) a GP73 diagnostic kit (cat. no. 1532405515; Shanghai Jianglai Biotechnology Co., Ltd.) and an MR-96A enzyme-linked immunoassay (cat. no. 1012; Mindray) were used.

Detection method. ELISA was performed for analyzing serum TAT-2 and GP73 expression levels in the two groups prior to and after treatment. First, the corresponding microplate wells were numbered sequentially with two negative control wells, two positive control wells and one blank control well in each plate. Next, the samples were diluted with sample dilution solution (1:1) and $50 \mu \mathrm{l}$ was added to the reaction wells. Next, $50 \mu \mathrm{l}$ of diluted standard or sample was added to the wells, immediately followed by the addition of $50 \mu \mathrm{l}$ of biotinylated antibody. The plate was covered, shaken gently to mix and incubated at $37^{\circ} \mathrm{C}$ for $1 \mathrm{~h}$. The solution in each well was discarded, each well was filled with detergent, shaken for $30 \mathrm{sec}$ and the detergent was discarded. Subsequently, the plate was patted with absorbent paper to absorb residual detergent and the process was repeated thrice. Termination solution $(50 \mu \mathrm{l})$ was added immediately after removing the plate from the dark. The optical density value of each well was measured within 15 min after the addition of the termination solution at a wavelength of $450 \mathrm{~nm}$.

Statistical analysis. SPSS 22.0 (IBM Corp.) was employed for statistical analyses. Count data are expressed as numbers and percentages and were compared using a Chi-squared test. An unpaired Student's t-test was used for comparisons 
Table I. Demographic and clinical data of the patients.

\begin{tabular}{|c|c|c|c|c|}
\hline Factors & Group A $(n=86)$ & Group B $(n=75)$ & $\mathrm{t} / \chi^{2}$ value & P-value \\
\hline Sex & & & 0.022 & 0.883 \\
\hline Male & $56(65.12)$ & $48(64.00)$ & & \\
\hline Female & $30(34.88)$ & $27(36.00)$ & & \\
\hline Age (years) & $57.36 \pm 2.87$ & $58.06 \pm 2.84$ & 1.551 & 0.123 \\
\hline Body mass index $\left(\mathrm{kg} / \mathrm{m}^{2}\right)$ & $22.65 \pm 2.52$ & $22.34 \pm 2.37$ & 0.800 & 0.425 \\
\hline Educational level & & & 0.088 & 0.766 \\
\hline High school and below & $41(47.67)$ & $34(45.33)$ & & \\
\hline Above high school & $45(52.33)$ & $41(54.67)$ & & \\
\hline Smoking history & & & 0.179 & 0.672 \\
\hline Yes & $51(59.30)$ & $42(56.00)$ & & \\
\hline No & $35(40.70)$ & $33(44.00)$ & & \\
\hline Drinking history & & & 0.515 & 0.473 \\
\hline Yes & $22(25.58)$ & $23(30.67)$ & & \\
\hline No & $64(74.42)$ & $52(69.33)$ & & \\
\hline Residence & & & 0.159 & 0.690 \\
\hline Urban & $63(73.26)$ & $57(76.00)$ & & \\
\hline Rural & $23(26.74)$ & $18(24.00)$ & & \\
\hline Body temperature $\left({ }^{\circ} \mathrm{C}\right)$ & $36.62 \pm 0.30$ & $36.69 \pm 0.28$ & 1.523 & 0.130 \\
\hline Erythrocytes (x1012/1) & $6.58 \pm 0.49$ & $6.61 \pm 0.51$ & 0.380 & 0.704 \\
\hline Leukocytes (x109/1) & $12.26 \pm 3.53$ & $12.32 \pm 3.61$ & 0.107 & 0.915 \\
\hline Pathological type & & & 0.396 & 0.821 \\
\hline Uplift type & $30(34.88)$ & $26(34.67)$ & & \\
\hline Superficial type & $32(37.21)$ & $25(33.33)$ & & \\
\hline Depressed type & $24(27.91)$ & $24(32.00)$ & & \\
\hline Infiltration depth & & & 0.126 & 0.939 \\
\hline Mucosal layer & $36(41.86)$ & $33(44.00)$ & & \\
\hline Mucosal muscular layer & $19(22.09)$ & $15(20.00)$ & & \\
\hline Submucosal layer & $31(36.05)$ & $27(36.00)$ & & \\
\hline Lymph node metastasis & & & 0.715 & 0.398 \\
\hline Yes & $17(19.77)$ & $19(25.33)$ & & \\
\hline No & $69(80.23)$ & $56(74.67)$ & & \\
\hline Site & & & 0.770 & 0.681 \\
\hline Upper $1 / 3$ & $7(8.14)$ & $9(12.00)$ & & \\
\hline Medium 1/3 & $44(51.16)$ & $35(46.67)$ & & \\
\hline Bottom 1/3 & $35(40.70)$ & $31(41.33)$ & & \\
\hline
\end{tabular}

Values are expressed as $\mathrm{n}(\%)$ or the mean \pm standard deviation. Groups: A, patients with EGC treated with endoscopic submucosal dissection; $\mathrm{B}$, patients with EGC treated with endoscopic mucosal resection. EGC, early gastric cancer.

between the two groups. Intergroup comparisons between the pre-treatment and the post-treatment data were analyzed by one-way ANOVA, whereas the pairwise comparisons were analyzed by the Bonferroni post hoc test. Kaplan-Meier curves were drawn to establish survival curves for the two groups and a log-rank test was performed to evaluate differences between the survival curves.

\section{Results}

General information. Comparison of clinical data between the two groups indicated no significant differences in terms of parameters such as sex, age, body mass index, education level, smoking history, drinking history, residence, body temperature, erythrocyte count, leukocyte count, pathological classification, infiltration depth and lymph node metastasis or tumor site between the two groups ( $\mathrm{P}>0.05$; Table I).

Treatment effectiveness. The results regarding treatment effectiveness were as follows: In group $\mathrm{A}$, the treatment was markedly effective in 69 cases $(80.23 \%)$, effective in $14(16.28 \%)$ and ineffective in 3 patients $(3.49 \%)$, with a total treatment effectiveness of $96.51 \%$. In group B, the treatment was markedly effective in 48 cases $(64.00 \%)$, effective in 
Table II. Comparison of clinical efficacy between groups A and B.

\begin{tabular}{|c|c|c|c|c|}
\hline Category & Group A $(n=86)$ & Group B $(n=75)$ & $\chi^{2}$ value & P-value \\
\hline Marked clinical efficacy ${ }^{a}$ & $69(80.23)$ & $48(64.00)$ & 5.315 & 0.021 \\
\hline Effective & $14(16.28)$ & $12(16.00)$ & 0.002 & 0.962 \\
\hline Ineffective & $3(3.49)$ & $15(20.00)$ & 11.000 & 0.001 \\
\hline Total effectiveness & $83(96.51)$ & $60(80.00)$ & 11.000 & 0.001 \\
\hline
\end{tabular}

${ }^{a}$ Clinical efficacy index for gastrointestinal function indicators and prognosis after surgery (34). Values are expressed as $\mathrm{n}$ (\%). Groups: A, patients with EGC treated with endoscopic submucosal dissection; B, patients with EGC treated with endoscopic mucosal resection. EGC, early gastric cancer.

A

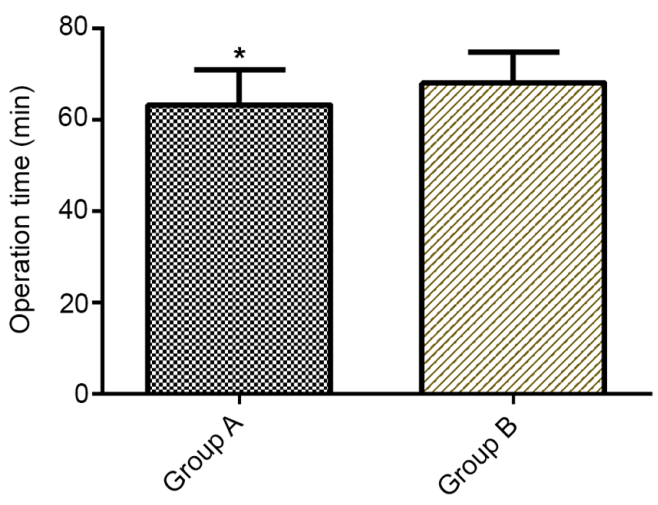

B

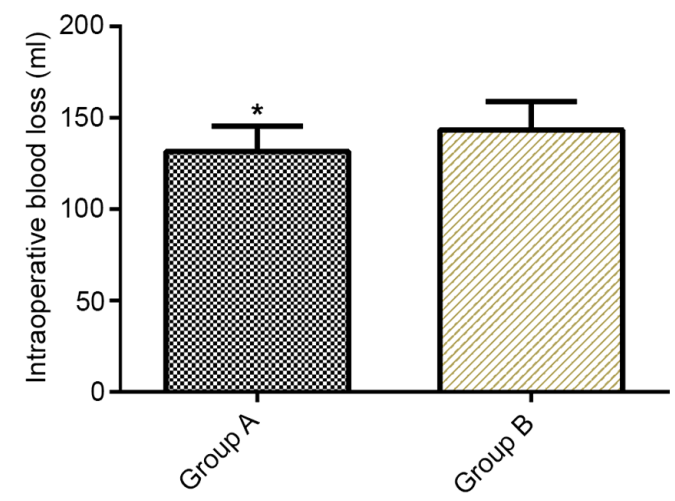

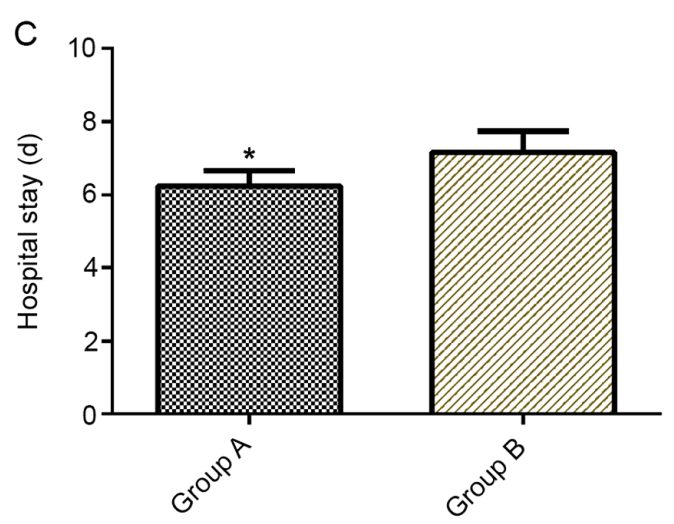

Figure 1. Comparison of (A) operation time, (B) intraoperative blood loss and (C) length of hospital stay between groups A and B. The operation time was shorter in group A than in group B, intraoperative blood loss was less in group A than in group B and the length of hospital stay was shorter in group A than in group B. ${ }^{*} \mathrm{P}<0.05$ vs. group B. Groups: A, patients with EGC treated with endoscopic submucosal dissection; B, patients with EGC treated with endoscopic mucosal resection. EGC, early gastric cancer; d, days.

$12(16.00 \%)$ and ineffective in 15 patients $(20.00 \%)$, with a total effectiveness of $80.00 \%$. The total treatment effectiveness was significantly higher in group A than in group B $(\mathrm{P}<0.05$; Table II).

Comparison of complications. There were 6 cases $(8.00 \%)$ of nausea and vomiting, $4(5.33 \%)$ of bleeding due to perforation occurring intraoperatively and $4(5.33 \%)$ of abdominal distension and abdominal pain after treatment in group B (total adverse reaction/complication rate, 18.66\%). The corresponding post-treatment adverse reactions/complications in group A were 8 (9.30\%), $6(6.98 \%)$ and 7 (8.14\%), respectively (total adverse reaction/complication rate, $24.42 \%$; Table III).
Comparison of operation time, intraoperative blood loss and length of hospital stay. Operation time, intraoperative blood loss and length of hospital stay were significantly lower in group $\mathrm{A}$ than in group $\mathrm{B}(\mathrm{P}<0.05$; Fig. 1$)$.

Comparison of serum TAT-2 and GP73 expression levels prior to and after treatment. No significant difference was observed in serum TAT-2 and GP73 expression levels between the two groups prior to treatment $(\mathrm{P}>0.05)$. After treatment, serum TAT-2 expression levels decreased in both groups $(\mathrm{P}<0.05)$ and serum TAT-2 expression levels were lower in group A than in group $\mathrm{B}(\mathrm{P}<0.05)$. After treatment, serum GP73 expression levels increased in both groups $(\mathrm{P}<0.05$; Fig. 2$)$. 
Table III. Comparison of adverse events and complications between groups A and B.

\begin{tabular}{|c|c|c|c|c|}
\hline Item & Group A $(n=86)$ & Group B $(n=75)$ & $\chi^{2}$ value & P-value \\
\hline Nausea and vomiting & $8(9.30)$ & $6(8.00)$ & 0.083 & 0.773 \\
\hline Bleeding due to perforation in the perioperative phase & $6(6.98)$ & $4(5.33)$ & 0.186 & 0.667 \\
\hline Abdominal distension and abdominal pain & $7(8.14)$ & $4(5.33)$ & 0.496 & 0.481 \\
\hline Total incidence & $21(24.42)$ & $14(18.66)$ & 0.779 & 0.377 \\
\hline
\end{tabular}

Values are expressed as $\mathrm{n}(\%)$. Groups: A, patients with EGC treated with endoscopic submucosal dissection; B, patients with EGC treated with endoscopic mucosal resection. EGC, early gastric cancer.
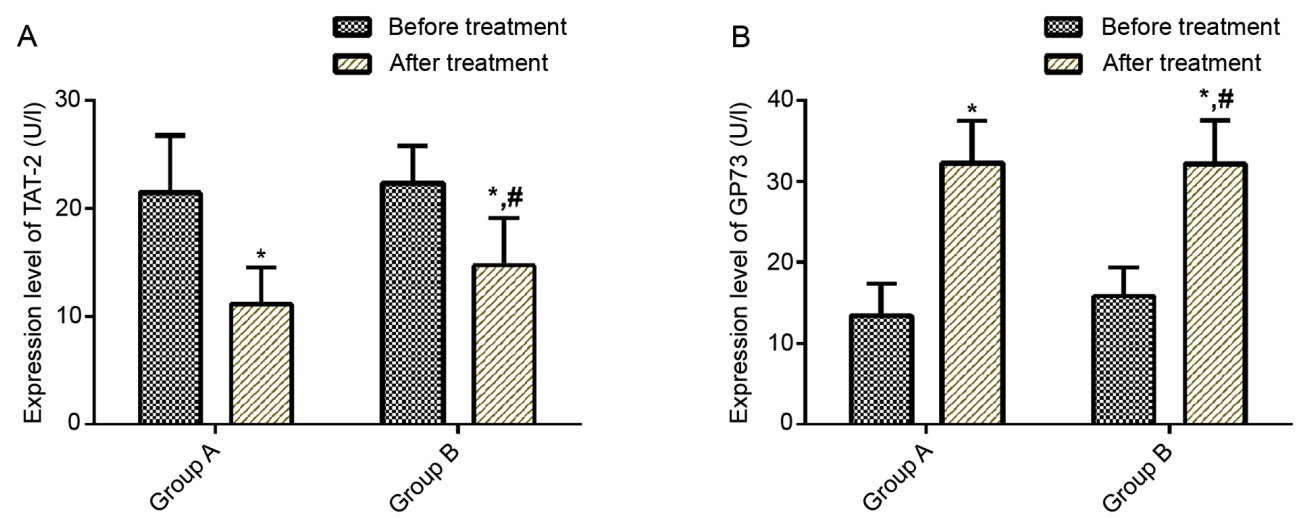

Figure 2. Comparison of serum TAT-2 and GP73 expression levels between groups A and B prior to and after treatment. (A) Comparison of serum TAT-2 expression level between groups A and B prior to and after treatment. No significant difference was noted in serum TAT-2 expression levels between the two groups prior to treatment $(\mathrm{P}>0.05)$, but it decreased in both groups after treatment $(\mathrm{P}<0.05)$. Serum TAT-2 expression levels were lower in group $B$ than in group A $(\mathrm{P}<0.05)$. (B) Comparison of serum GP73 expression level between groups A and B before and after treatment. There was no significant difference in serum GP73 expression level between the two groups before treatment $(\mathrm{P}>0.05)$, but it increased in both groups after treatment $(\mathrm{P}<0.05)$. Serum GP73 expression level was higher in group B than in group $\mathrm{A}(\mathrm{P}<0.05)$. ${ }^{*} \mathrm{P}<0.05$ vs. the same group prior to treatment; ${ }^{\# \mathrm{P}}<0.05$ vs. group A after treatment. Groups: A, patients with EGC treated with endoscopic submucosal dissection; B, patients with EGC treated with endoscopic mucosal resection. EGC, early gastric cancer; TAT-2, trypsinogen-2; GP73, Golgi protein 73.

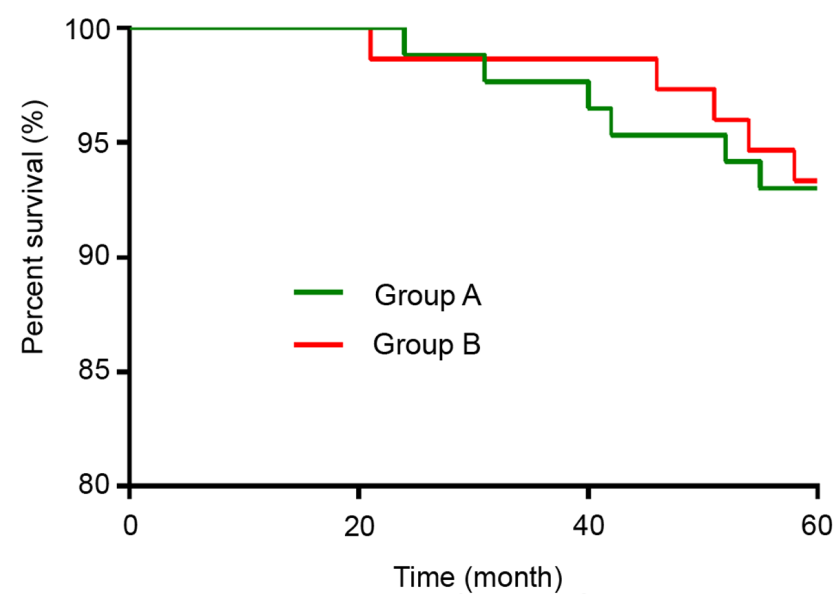

Figure 3. Kaplan-Meier curves for the five-year survival after surgery in groups A and B. Patients were followed up for 5 years and the overall survival rate was 93.17\%. The five-year survival rate of groups A and B was 93.02 and $93.33 \%$, respectively, with no significant difference $(\mathrm{P}=0.926)$. Groups: A, patients with EGC treated with endoscopic submucosal dissection; B, patients with EGC treated with endoscopic mucosal resection. EGC, early gastric cancer.

Five-year survival rate after treatment. All 161 patients were followed up for 5 years and 11 died during the follow-up period (5-year survival rate, 93.17\%). There were 6 deaths in group A (5-year survival rate, 93.02\%) and 5 in group B (5-year survival rate, 93.33\%). Kaplan-Meier survival curves revealed no significant differences in 5-year survival rate between the two groups ( $\mathrm{P}>0.05$; Fig. 3$)$.

\section{Discussion}

The pathogenesis of GC is complex with possible causes including Helicobacter pylori infection, environmental factors and genetic factors. EGC cells are confined to the gastric mucosa and submucosa and the 5-year survival rate of patients with EGC may reach $>90 \%$. However, if GC cells continue to develop and invade the muscular layer, the post-operative 5-year survival rate decreases to $30-50 \%(22,23)$. Therefore, timely and effective treatment of early-onset GC and EGC are of great importance for favorable patient outcomes.

ESD is a minimally invasive technique that evolved from endoscopic mucosectomy, which has the advantages of limited trauma, rapid recovery, high removal rate, fewer complications and lower surgical costs. It improves treatment effects and post-operative recovery and it has become one of the most common microsurgical procedures for the treatment of digestive tract cancer (24-26). Meng et al (27) retrospectively reviewed 126 cases of gastrointestinal stromal tumor with lesion diameters of $<2 \mathrm{~cm}$ and indicated that ESD was superior to laparoscopic 
surgery for submucosal tumors with smaller diameters. In addition, Bang et al (28) conducted a meta-analysis of 9 studies and concluded that ESD is a technically feasible method for the treatment of subepithelial tumors. The present study suggested that total treatment effectiveness was higher in group A than in group B, whereas no significant difference was observed in terms of incidence of complications between the two groups. Furthermore, the operation time, intraoperative blood loss and length of hospital stay were lower in group A than in group B. Certain clinical studies have suggested that ESD has an ideal efficacy in the treatment for EGC, with relatively few and controllable complications and relatively high safety and effectiveness. By studying long-term patient prognoses after ESD, Park et al (29) indicated that considering the resection rates of large lesions, the outcomes for patients treated with ESD were good and the recurrence rate was low. Ryu et al (30) reviewed ESD and cancer resection and their results suggested that the ESD group had a shorter operation time and fasting period than the surgical resection group. They suggested that ESD is an acceptable and effective treatment for EGC compared with surgical resection, which is consistent with the results of the present study.

Previous studies have demonstrated that TAT-2 and GP73 were abnormally expressed in GC. Song et al (31) reported that serum TAT2 expression levels were significantly increased in patients with GC compared with those in healthy subjects $(\mathrm{P}<0.05)$. In addition, its sensitivity was higher than that of the tumor markers CA242, CA50 and CEA. Furthermore, the specificity of serum TAT2 expression levels was $95 \%$, suggesting that it may be used as a novel tumor marker. Chen et al (32) reported that GP73 mRNA and protein expression in GC tissues were lower than those of adjacent normal tissues, which was associated with the differentiation degree of GC and the sex of patients. In the present study, serum TAT-2 expression levels decreased in both groups, whereas serum GP73 expression levels increased after treatment. Serum TAT-2 expression levels were lower but serum GP73 expression levels were higher in group A than in group B, indicating that ESD improved EGC, reduced serum TAT-2 expression levels and increased serum GP73 expression levels. Serum TAT-2 and GP73 expression levels may be associated with the severity of EGC, but their relationship has not been thoroughly discussed in the present study. Regarding survival, the 5-year survival rate of group A and group B was 93.02 and $93.33 \%$, respectively, which were not significantly different, indicating that the effects of the two treatments on survival were not different. These results are consistent with those reported by Rong et al (33) who reported no significant difference in 5-year morbidity and mortality between ESD and surgical resection.

The study subjects were selected in strict accordance with the inclusion and exclusion criteria in the present study. No significant differences were noted in clinical baseline data including sex, age, body mass index, education level, smoking history or drinking history between both groups, which ensured rigor and reliability of the study. However, there are certain limitations to the study. First, due to the retrospective collection of patient data, the obtained data may have been influenced by subjective factors. Furthermore, the regulatory mechanisms of ESD in the treatment of EGC and its effects on TAT-2 and GP73 expression levels remain unclear, warranting further investigation in follow-up experiments.
In conclusion, compared with EMR, ESD was more efficient in the treatment of EGC, shortening the operation time and length of hospital stay, reducing intraoperative blood loss, decreasing serum TAT-2 expression levels and increasing serum GP73 expression levels. However, no significant differences were noted in adverse reactions or survival between the two groups.

\section{Acknowledgements}

Not applicable.

\section{Funding}

No funding was received.

\section{Availability of data and materials}

The datasets used and/or analyzed during the present study are available from the corresponding author on reasonable request.

\section{Authors' contributions}

$\mathrm{XH}, \mathrm{FL}$ and QJ conceived and designed the study and interpreted the results of the experiments. $\mathrm{HG}, \mathrm{ZJ}, \mathrm{PW}$ and $\mathrm{YL}$ performed the experiments. $\mathrm{HG}$ and $\mathrm{ZJ}$ authenticated the raw data in this paper. XH, FL, HG, ZJ, PW, YL and QJ analyzed data. PW and YL prepared figures. QJ drafted the manuscript and $\mathrm{XH}$ and QJ edited and revised the manuscript. All authors approved the final version of the manuscript.

\section{Ethics approval and consent to participate}

The study was approved by the Ethics Committee of the Eighth Affiliated Hospital of Guangxi Medical University (Guigang, China). All study participants provided written informed consent prior to participating in the study.

\section{Patient consent for publication}

Not applicable.

\section{Competing interests}

The authors declare that they have no competing interests.

\section{References}

1. Bray F, Ferlay J, Soerjomataram I, Siegel RL, Torre LA and Jemal A: Global cancer statistics 2018: GLOBOCAN estimates of incidence and mortality worldwide for 36 cancers in 185 countries. CA Cancer J Clin 68: 394-424, 2018.

2. Wu HQ, Wang HY, Xie WM, Wu SL, Li ZF, Zhang XM and $\mathrm{Li} \mathrm{H}$ : Scanning photoacoustic imaging of submucosal gastric tumor based on a long focused transducer in phantom and in vitro experiments. J Innov Opt Health Sci 12: 1950011, 2019.

3. Rahman R, Asombang AW and Ibdah JA: Characteristics of gastric cancer in Asia. World J Gastroenterol 20: 4483-4490, 2014.

4. Shen L, Li J, Xu J, Pan H, Dai G, Qin S, Wang L, Wang J, Yang Z, Shu Y, et al: Bevacizumab plus capecitabine and cisplatin in Chinese patients with inoperable locally advanced or metastatic gastric or gastroesophageal junction cancer: Randomized, double-blind, phase III study (AVATAR study). Gastric Cancer 18: 168-176, 2015. 
5. Zeng H, Zheng R, Guo Y, Zhang S, Zou X, Wang N, Zhang L, Tang J, Chen J, Wei K, et al: Cancer survival in China, 2003-2005: A population-based study. Int J Cancer 136: 1921-1930, 2015.

6. Yu L, Wu D, Gao H, Balic JJ, Tsykin A, Han TS, Liu YD, Kennedy CL, Li JK, Mao JQ, et al: Clinical utility of a STAT3-regulated miRNA-200 family signature with prognostic potential in early gastric cancer. Clin Cancer Res 24: 1459-1472, 2018.

7. Hondo FY, Kishi H, Safatle-Ribeiro AV, Pessorrusso FC, Ribeiro U Jr and Maluf-Filho F: Characterization of the mucin phenotype can predict gastric cancer recurrence after endoscopic mucosal resection. Arq Gastroenterol 54: 308-314, 2017.

8. Kim SG, Park CM, Lee NR, Kim J, Lyu DH, Park SH, Choi IJ, Lee WS, Park SJ, Kim JJ, et al: Long-term clinical outcomes of endoscopic submucosal dissection in patients with early gastric cancer: A prospective multicenter cohort study. Gut Liver 12 : 402-410, 2018.

9. Pan J, Zhang X, Shi Y and Pei Q: Endoscopic mucosal resection with suction vs. endoscopic submucosal dissection for small rectal neuroendocrine tumors: A meta-analysis. Scand J Gastroenterol 53: 1139-1145, 2018.

10. Seewald S, Ang TL, Pouw RE, Bannwart F and Bergman JJ: Management of early-stage adenocarcinoma of the esophagus: Endoscopic mucosal resection and endoscopic submucosal dissection. Dig Dis Sci 63: 2146-2154, 2018.

11. Hu JS, Wu DW, Liang S and Miao XY: GP73, a resident Golgi glycoprotein, is sensibility and specificity for hepatocellular carcinoma of diagnosis in a hepatitis B-endemic Asian population. Med Oncol 27: 339-345, 2010.

12. Riener MO, Stenner F, Liewen H, Soll C, Breitenstein S, Pestalozzi BC, Samaras P, Probst-Hensch N, Hellerbrand C, Müllhaupt B, et al: Golgi phosphoprotein 2 (GOLPH2) expression in liver tumors and its value as a serum marker in hepatocellular carcinomas. Hepatology 49: 1602-1609, 2009.

13. Sun Y, Yang H, Mao Y, Xu H, Zhang J, Li G, Lu X, Sang X, Zhao H, Zhong S, et al: Increased Golgi protein 73 expression in hepatocellular carcinoma tissue correlates with tumor aggression but not survival. J Gastroenterol Hepatol 26: 1207-1212, 2011.

14. Fujimura T, Ohta T, Kitagawa H, Fushida S, Nishimura GI, Yonemura Y, Elnemr A, Miwa K and Nakanuma Y: Trypsinogen expression and early detection for peritoneal dissemination in gastric cancer. J Surg Oncol 69: 71-75, 1998.

15. Itkonen O: Human trypsinogens in the pancreas and in cancer. Scand J Clin Lab Invest 70: 136-143, 2010.

16. Ichikawa Y, Koshikawa N, Hasegawa S, Ishikawa $T$, Momiyama N, Kunizaki C, Takahashi M, Moriwaki Y, Akiyama $\mathrm{H}$, Yamaoka $\mathrm{H}$, et al: Marked increase of trypsin(ogen) in serum of linitis plastica (gastric cancer, borrmann 4) patients. Clin Cancer Res 6: 1385-1388, 2000.

17. Esaki M, Suzuki S, Hayashi Y, Yokoyama A, Abe S, Hosokawa T, Tsuruta S, Minoda Y, Hata Y, Ogino H, et al: Propensity score-matching analysis to compare clinical outcomes of endoscopic submucosal dissection for early gastric cancer in the postoperative and non-operative stomachs. BMC Gastroenterol 18: 125, 2018.

18. Hahn KY, Park CH, Lee YK, Chung H, Park JC, Shin SK, Lee YC, Kim HI, Cheong JH, Hyung WJ, et al: Comparative study between endoscopic submucosal dissection and surgery in patients with early gastric cancer. Surg Endosc 32: 73-86, 2018.

19. Yuan Y: A survey and evaluation of population-based screening for gastric cancer. Cancer Biol Med 10: 72-80, 2013.

20. Lamb CA, Kennedy NA, Raine T, Hendy PA, Smith PJ, Limdi JK, Hayee B, Lomer MCE, Parkes GC, Selinger C, et al; IBD guidelines eDelphi consensus group: British Society of Gastroenterology consensus guidelines on the management of inflammatory bowel disease in adults. Gut 68 (Suppl 3): s1-s106, 2019.
21. Askar H, Di Gianfilippo R, Ravida A, Tattan M, Majzoub J and Wang HL: Incidence and severity of postoperative complications following oral, periodontal, and implant surgeries: A retrospective study. J Periodontol 90: 1270-1278, 2019.

22. Buckland G, Travier N, Huerta JM, Bueno-de-Mesquita HB, Siersema PD, Skeie G, Weiderpass E, Engeset D, Ericson U, Ohlsson B, et al: Healthy lifestyle index and risk of gastric adenocarcinoma in the EPIC cohort study. Int J Cancer 137: 598-606, 2015

23. Ghoshal UC, Kumar S, Krishnani N, Kumari N, Chourasia D and Tripathi S: Serological assessment of gastric intestinal metaplasia and atrophy using pepsinogen-I, pepsinogen-II and gastrin-17 levels in a low incidence area of gastric cancer endemic for H. pylori infection. Trop Gastroenterol 32: 292-298, 2011.

24. Ono S, Fujishiro M, Niimi K, Goto O, Kodashima S, Yamamichi N and Omata M: Long-term outcomes of endoscopic submucosal dissection for superficial esophageal squamous cell neoplasms. Gastrointest Endosc 70: 860-866, 2009.

25. Onozato Y, Kakizaki S, Ishihara H, Iizuka H, Sohara N, Okamura S, Mori M and Itoh H: Endoscopic submucosal dissection for rectal tumors. Endoscopy 39: 423-427, 2007.

26. Saito Y, Uraoka T, Matsuda T, Emura F, Ikehara H, Mashimo Y, Kikuchi T, Fu KI, Sano Y and Saito D: Endoscopic treatment of large superficial colorectal tumors: A case series of 200 endoscopic submucosal dissections (with video). Gastrointest Endosc 66: 966-973, 2007.

27. Meng Y, Li W, Han L, Zhang Q, Gong W, Cai J, Li A, Yan Q, Lai Q, Yu J, et al: Long-term outcomes of endoscopic submucosal dissection versus laparoscopic resection for gastric stromal tumors less than $2 \mathrm{~cm}$. J Gastroenterol Hepatol 32: 1693-1697, 2017.

28. Bang CS, Baik GH, Shin IS, Suk KT, Yoon JH and Kim DJ: Endoscopic submucosal dissection of gastric subepithelial tumors: A systematic review and meta-analysis. Korean J Intern Med (Korean Assoc Intern Med) 31: 860-871, 2016.

29. Park JC, Lee SK, Seo JH, Kim YJ, Chung H, Shin SK and Lee YC: Predictive factors for local recurrence after endoscopic resection for early gastric cancer: Long-term clinical outcome in a single-center experience. Surg Endosc 24: 2842-2849, 2010.

30. Ryu SJ, Kim BW, Kim BG, Kim JH, Kim JS, Kim JI, Park JM Oh JH, Kim TH, Kim JJ, et al: Endoscopic submucosal dissection versus surgical resection for early gastric cancer: A retrospective multicenter study on immediate and long-term outcome over 5 years. Surg Endosc 30: 5283-5289, 2016.

31. Song WC, Qiao XL and Gao XZ: A comparison of endoscopic submucosal dissection (ESD) and radical surgery for early gastric cancer: A retrospective study. World J Surg Oncol 13: 309, 2015.

32. Chen LG, Wang HJ, Yao HB, Guan TP, Wu F, He XJ, Ma YY, Tao HQ and Ye ZY: GP73 is down-regulated in gastric cancer and associated with tumor differentiation. World J Surg Oncol 11: $132,2013$.

33. Rong L, Cai Y, Nian W, Wang X, Liang J, He Y and Zhang J: Efficacy comparison between surgical resection and endoscopic submucosal dissection of early gastric cancer in a domestic single center. Zhonghua Wei Chang Wai Ke Za Zhi 21: 190-195, 2018 (In Chinese)

This work is licensed under a Creative Commons Attribution-NonCommercial-NoDerivatives 4.0 International (CC BY-NC-ND 4.0) License. 